\title{
Fuzzy DEMATEL-QFD for Designing Supply Chain of Shipbuilding Materials Based on Flexible Strategies
}

\author{
Jing Zhu ${ }^{1}$, Haiyan Wang ${ }^{1,2, * \mathbb{C}}$ and Jing $\mathrm{Xu}^{3}$ \\ 1 School of Transportation and Logistics Engineering, Wuhan University of Technology, Wuhan 430063, China; \\ 1322339166@whut.edu.cn \\ 2 National Engineering Research Center for Water Transport Safety, Wuhan University of Technology, \\ Wuhan 430063, China \\ 3 Shanghai Waigaoqiao Shipbuilding Co., Ltd., Shanghai 200000, China; xujing@chinasws.com \\ * Correspondence: hywang777@whut.edu.cn
}

check for updates

Citation: Zhu, J.; Wang, H.; Xu, J. Fuzzy DEMATEL-QFD for Designing Supply Chain of Shipbuilding Materials Based on Flexible Strategies. J. Mar. Sci. Eng. 2021, 9, 1106. https://doi.org/10.3390/ jmse9101106

Academic Editor: José A. F. O. Correia

Received: 24 August 2021

Accepted: 7 October 2021

Published: 12 October 2021

Publisher's Note: MDPI stays neutral with regard to jurisdictional claims in published maps and institutional affiliations.

Copyright: (c) 2021 by the authors. Licensee MDPI, Basel, Switzerland. This article is an open access article distributed under the terms and conditions of the Creative Commons Attribution (CC BY) license (https:// creativecommons.org/licenses/by/ $4.0 /)$.

\begin{abstract}
Shipbuilding materials are characterized by diverse kinds, large quantities and wide distribution of suppliers, which make the supply network complicated. Complex networks have led to increasing uncertainties that may cause disruptions in the supply chain. Flexibility is an effective measure to cope with uncertainty, thus this paper aims to integrate flexibility into the supply chain of shipbuilding materials and explore supply, logistics, organization and quality flexibility by focusing on the requirements of shipbuilding enterprises. This paper combines Quality Function Deployment (QFD), fuzzy theory and Decision Making Trial and Evaluation Laboratory (DEMATEL) methods to guide practical design. After determining five customer requirements (CRs) and 24 design requirements (DRs), QFD links CRs and DRs to determine the most important feasible DRs for improvement of supply chain flexibility. Research results reveal that the most important design requirements can be summarized into four aspects, namely domestic procurement, supply chain member cooperation, supplier supervision, and emergency response construction. Moreover, it is found that long-term strategic partnerships with suppliers and strategic logistics outsourcing are effective strategies. This paper provides insight into implications for strategic decisions of shipbuilding enterprises.
\end{abstract}

Keywords: fuzzy DEMATEL-QFD; shipbuilding materials; supply chain design; flexible strategies

\section{Introduction}

Shipbuilding, as a system of complex construction projects, is increasingly important for the cooperation of a number of partners during its long production cycle [1]. Different from the conventional manufacturing industry, products involved in the shipbuilding industry are characterized by large size, high specificity and customization of parts, which makes its upstream suppliers widely distributed geographically. Indeed, managing a logistics activity that involves a global network of suppliers is a major challenge for most shipbuilding companies [2]. In the face of a complex supply network and competitive ship market, the shipbuilding supply chain is of great importance to shipbuilding enterprises [3]. In a shipbuilding supply chain with shipbuilding enterprises as the core and many suppliers, supporting enterprises and other related organizations involved, the cooperation among nodes is easily affected by the complex relationship between participants [4]. At this time, uncertain factors such as demand plan change, order information asymmetry, raw material price rise, supplier delivery cycle problems are the reality that must be considered to ensure the timely delivery of materials. From a more specific point of view, the supporting work of a large number of materials is included in the process of ship construction, and multi-level warehousing and distribution, as well as multi-role supply and demand coordination, runs through the whole logistics process, which inevitably aggravates the complexity and vulnerability of the supply chain of shipbuilding materials. 
Therefore, sources of uncertainty increase accordingly and exist in the whole process of the supply chain, that is, from the purchase order to actual use by the shipyard, which includes material production, transportation, arrival inspection and warehousing. How to deal with this change is interesting, but there is still a lack of comprehensive research in this area. Flexibility represents an enterprise's ability to respond to environmental changes by integrating internal and external resources. In this regard, the relationship between flexibility and uncertainty continues to be widely discussed. Based on this, this paper attempts to analyze supply chain flexibility aiming at uncertainty in the supply chain.

At present, the literature has dedicated significant emphasis to studying flexibility and extending it to the supply chain, and mentions that flexibility is a favorable tool to solve the uncertainty of the supply chain. Moreover, a wealth of supply chain flexibility dimensions and specific flexibility strategy research results have been formed $[5,6]$. In view of this, aiming at uncertainties existing in the supply chain of shipbuilding materials, this paper puts forward an idea of building a supply chain with flexible characteristics based on flexible strategy, so as to ensure normal flow of materials in the supply chain network and realize effective management of various activities along the supply chain. Based on the above analysis, three main questions arise in designing a supply chain with flexible characteristics: One is what kind of flexibility should be considered? The other is how to integrate flexibility into the construction of the supply chain? The last is what method is used to achieve supply chain flexibility?

To solve the aforementioned questions, this paper first summarizes flexible strategies of the supply chain from five aspects of supply, logistics, information, organization and quality by combining the characteristics of the supply chain of shipbuilding materials and referring to a relevant literature review. Then, DFD is employed to build a flexible supply chain due to its good applicability in designing a supply chain, in which five standards are utilized to better reveal customer requirements (CRs) of the supply chain, including quantity and quality assurance of materials, delivery reliability, timeliness of response to changes in demand, punctuality of arrival and cost control. Meanwhile, the summarized flexible strategies are taken as design requirements (DRs) of the supply chain. Subsequently, owing to inherent ambiguity and imprecision in describing the relationship between CRs and DRs with regard to QFD, the intuitionistic fuzzy concept is introduced to obtain accurate results. In addition, considering the correlation between CR and DR indicators, DEMATEL, which can clarify the causality of factors and internal influence, is also incorporated into QFD. Finally, a Hybrid Fuzzy DEMATEL-QFD method is proposed to achieve prioritization of DRs, and to identify the most important flexible strategies for building a supply chain of shipbuilding materials with flexible characteristics. This study provides a reference for supply chain management in the shipbuilding industry.

After the introduction, Section 2 mainly reviews the relevant literature and highlights the research gap. Section 3 presents the approach and steps to conduct supply chain design of shipbuilding materials. Section 4 obtains the original ranking of DRs through a case study of a shipbuilding enterprise and discusses the results. The main work is concluded in Section 5.

\section{Literature Review}

\subsection{Shipbuilding Supply Chain Risk}

Generally speaking, supply chain refers to the network chain structure formed by upstream and downstream enterprises that provide products or services to end customers in the process of production and circulation, which includes the flow of information, goods and capital [7]. It is easy to understand that the key objective of supply chain operation is to deliver a product to the designated place in the correct quantity, quality and state, requiring joint cooperation of the members of the supply chain system. Inevitably, there are always risks in this process which make an impact on goal achievement, such as purchase order errors, transportation disruptions, communication difficulties, limited supplier capabilities, vertical management of the supply chain, etc. A large amount of the literature on supply 
chain risks have a comprehensive classification of risks, which are demand risk, delay risk, interruption risk, inventory risk, procurement risk, information risk, transportation risk and management risk, and unanimously believe effective management of supply chain is indispensable [8-11].

Realizing the significance of supply chain management, diverse industries have carried out related research, and the shipbuilding industry is an important one. In regard to characteristics of the shipbuilding industry, it is believed that the shipbuilding supply chain, with shipbuilding enterprises as the core, connects suppliers, supporting enterprises, cooperative factories, shipbuilding enterprises and shipowners, etc. into a whole network chain structure from purchasing raw materials such as steel and welding materials and ordering auxiliary products such as main engine and instrument to final assembly and delivery of vessels in each section [3]. Shipbuilding is generally subordinated to large-scale systems engineering with a long system cycle and requires many partners to work together, which brings complexity and vulnerability to the shipbuilding supply chain [12]. In this context, shipbuilding, like most construction projects, is fraught with similar uncertainties, containing fluctuating demand cycles, product requirements for specific projects, uncertain production conditions, etc., and accompanied by a great mass of information, personnel, equipment, and materials to be managed [13]. From a more specific perspective, the dynamic and complex characteristics of partners, processes and organizational structure of the shipbuilding supply chain make it fundamentally vulnerable to risks that may appear in any nodes in the chain [14]. In view of this, managing various activities in a global supply network chain is one of the main challenges faced by most shipbuilding companies [2]. Yue and Zhang [3] put forward that the shipbuilding supply chain risk refers to the negative impact of uncertain factors on the members of the supply chain or the damage to the operating environment, which leads to failure in achieving the target plan. The author also states that potential risks in the shipbuilding supply chain would disrupt the cooperation between nodes. In order to explain the risks more clearly, he divides the risks into external environmental risks such as poor transportation environment and international politics, together with operational risks including information interruption, supply risk, organizational risk, information risk, etc. Crispim, Fernandes, and Rego [15] establish a framework that combines the Delphi method, visualization chart, and Bayesian network for risk research of military shipbuilding projects. He summarizes the risks into six aspects, namely supplier or contract failure, insufficient resources, lack of labor quality, product quality problems, complex information, and planning and demand errors. The results reveal that the higher probability of occurrence is in production, contract, demand and planning errors. Some scholars have identified 30 risk factors from both internal and external aspects based on the perspective of the entire shipbuilding industry and believe that internal risks should be focused on [16]. Ferreira [11] analyzes the main risks of the Brazilian shipbuilding industry and systematically studies the possibility of risk occurrence, source of risk and corresponding risk mitigation strategy. Furthermore, Mello and Strandhagen [2] propose that effective supply chain management can be utilized to mitigate shipbuilding supply chain risks, such as improving relationships with suppliers and employing appropriate information tools.

\subsection{Supply Chain Flexibilities}

Responding to a diversified demand and a dynamically fluctuating environment is a major challenge for both the company and the supply chain. For industries facing customized needs, flexibility is a major feature of supply chains with the reason that it reflects the capability of enterprises and supply chains to cope with the diversity of demand and environmental uncertainties.

A variety of uncertainties existing in the operation of the supply chain, including market demand fluctuations, advanced supply time, product quality problems, plan changes, and information delays. As a matter of fact, unpredictable volatility in the supply chain is reflected in upstream suppliers, downstream customers, and industry competitors [17]. 
It is important that managers have a comprehensive understanding of the internal and external relationships in the supply chain as well as the upstream and downstream relationships [18]. Based on this, a core problem arises here, that is, how to cooperate with all participants in the supply chain to effectively deal with the uncertainty. While the match between flexibility and environmental uncertainty is a good way to solve this problem [5]. Regarding flexibility, supply chain flexibility can be defined as the ability of the supply chain to adapt to changes in market demand, which is usually manifested in the robustness of the relationship between the participants in the supply chain in an uncertain environment [19]. It should be noted that supply chain flexibility can be identified from a systematic and customer-oriented perspective, which means that it is the shared responsibility of multiple functional departments along the supply chain and strives to increase customer value [20]. Moreover, scholars have reached a consensus that supply chain flexibility refers to the ability to respond quickly and cost-effectively to various uncertainties in the supply chain [21-23]. Owning to the extensive role of flexibility, research on various kinds of flexibility in the supply chain has been paid increasing attention. In view of the uncertainties existing in complicated markets, many scholars have incorporated numerous types of flexibility into the supply chain in compliance with demand characteristics, contributing to the supply chain flexibility with multi-dimensional characteristics [6]. Multidimensional supply chain flexibility has been extensively studied in recent years, and most of the literature mentions supply chain flexibility in terms of procurement, organization, operation, logistics and information aspects. The ability to respond to the ever-changing demand for goods procurement and supply can be summed up as procurement flexibility, which embraces sourcing flexibility [24] and supply flexibility [25]. Flexibility in an organizational aspect means managing the relationships among members of the supply chain and coordinating the workforce to meet customer or service requirements, thus, labor flexibility [26] and organizational flexibility [27] are included. Correspondingly, in order to further deal with demand fluctuations, relevant scholars have defined volume flexibility at the operational level [20,24]. Furthermore, flexibility with respect to the logistics aspect relates to the ability to adjust or adapt to cargo transportation, storage and delivery, embracing storage flexibility, routing flexibility, delivery flexibility and transshipment flexibility $[24,27,28]$. Related research also shows that information flexibility, that is, the effectiveness and timeliness of information obtained by each member of the supply chain, is also a favorable strategy for quickly responding to uncertain demands [29].

We can conclude that scholars have established influential flexible aspects to address different uncertainties that may exist in the supply chain. Based on this, some of the literature further explores the role of supply chain flexibility. In order to clarify the relationship between uncertainty, flexibility and enterprise performance, Merschmann and Thonemann [5] utilize structural equation modeling to investigate German enterprises. The obtained evidence reveals that companies with highly flexible supply chains are better than those with less flexibility in a highly uncertain environment. Sreedevi and Saranga [30] believe that companies with a high degree of environmental uncertainty also face higher risks in terms of supply interruption, production and delivery delays. By using the data of 91 Indian manufacturing companies to conduct an empirical analysis to determine flexible strategies to reduce supply chain risks, the author concludes that a flexible strategy is constructive to alleviate the risks in respect to supply chain demand, supply and process. Furthermore, based on the quantitative method, Delic and Eyers [31] draw a conclusion that a flexible strategy can also have a positive impact on the supply chain by taking the automotive industry as an example. As elaborated before, it can be concluded that flexibility in the supply chain has important research significance. Moreover, Han, Wang, and Naim [32] test the direct and indirect effects of three types of information technology flexibility based on operational, strategic and technical on company performance and mention that flexible information connections between companies can effectively coordinate business and simplify the procurement process. The above research fully illustrates that flexibility has important application value in the supply chain. In view of this, scholars 
have proposed diversified flexible strategies for coping with different circumstances, as denoted in Table 1.

Table 1. Flexible strategies of supply chain.

\begin{tabular}{|c|c|c|}
\hline Flexible Aspects & Flexible Strategies & Source \\
\hline \multirow{12}{*}{ Supply flexibility } & Cooperation between strategic suppliers & [33] \\
\hline & $\begin{array}{l}\text { Collaboration among supply } \\
\text { chain members }\end{array}$ & [34] \\
\hline & $\begin{array}{l}\text { Long-term strategic partnership } \\
\text { with suppliers }\end{array}$ & {$[6,35]$} \\
\hline & Jointly develop products with suppliers & [36] \\
\hline & $\begin{array}{c}\text { A major supplier and substitutes in } \\
\text { times of crisis }\end{array}$ & [37] \\
\hline & $\begin{array}{c}\text { New supplier selection based on multiple } \\
\text { supplier strategy }\end{array}$ & [38] \\
\hline & $\begin{array}{l}\text { Changeover among various suppliers } \\
\text { regarding price, production and quality }\end{array}$ & [17] \\
\hline & Domestic procurement & {$[18,39]$} \\
\hline & Product postponement strategy & {$[25]$} \\
\hline & $\begin{array}{l}\text { flexible supply contracts regarding supply } \\
\text { periods and delivery schedules }\end{array}$ & [6] \\
\hline & Flexible price fluctuations in the contract & [37] \\
\hline & $\begin{array}{l}\text { Supplier obligations are stipulated } \\
\text { in the contract }\end{array}$ & [18] \\
\hline \multirow{5}{*}{ Information flexibility } & $\begin{array}{l}\text { Information sharing among supply } \\
\text { chain members }\end{array}$ & {$[40,41]$} \\
\hline & $\begin{array}{l}\text { Company internal communication based } \\
\text { on information system }\end{array}$ & [41] \\
\hline & Purchasing and supply data sharing & [40] \\
\hline & $\begin{array}{l}\text { Effective implementation of joint } \\
\text { replenishment and forecasting decisions }\end{array}$ & {$[42]$} \\
\hline & $\begin{array}{l}\text { Supply chain risk or reward sharing for } \\
\text { ensuring flexibility }\end{array}$ & [43] \\
\hline \multirow{6}{*}{ Logistics flexibility } & Strategic logistics outsourcing & {$[33,44]$} \\
\hline & $\begin{array}{c}\text { Alternative transportation modes and } \\
\text { routes under crisis }\end{array}$ & {$[36,44]$} \\
\hline & $\begin{array}{l}\text { Use tracking technology to increase } \\
\text { transportation transparency }\end{array}$ & [45] \\
\hline & $\begin{array}{l}\text { Supplier's agreement to guarantee } \\
\text { shipment as planned }\end{array}$ & [46] \\
\hline & $\begin{array}{l}\text { Inventory buffers in response to } \\
\text { increased demand }\end{array}$ & [47] \\
\hline & $\begin{array}{c}\text { Maintaining excess capacity in storage, } \\
\text { handling and transport }\end{array}$ & [18] \\
\hline \multirow{5}{*}{ Organizational flexibility } & $\begin{array}{c}\text { Integration of various departments within } \\
\text { the company }\end{array}$ & [39] \\
\hline & Vertical integration of the supply chain & [18] \\
\hline & Labor training & [6] \\
\hline & $\begin{array}{l}\text { Emergency response mechanism for } \\
\text { unexpected accidents }\end{array}$ & [6] \\
\hline & Teamwork towards problems & [48] \\
\hline
\end{tabular}

\subsection{QFD and Its Application in Supply Chain}

As a customer-driven product development method and an important tool for practicing total quality management, Quality Function Deployment (QFD) is used to integrate customer requirements into the design goals of a product or project [49]. QFD was first proposed by Japanese quality management expert Akao Yoji. The basic understanding of QFD is that quality is what customers expect, how functions are designed to meet customer 
needs, and deployment is how to implement customer needs in design. The QFD process is completed through a series of charts and matrices, and the HOQ, which realizes the transformation of customer requirements and product design requirements, is the basis and core tool for establishing QFD system [50]. As a method with strong efficacy and unique advantages in planning, QFD has been widely employed in the fields of product development [51], design management [52,53] and optimization decision [54,55]. At the same time, QFD has been successfully extended to the supply chain management field. Zarei, Fakhrzad, and Paghaleh [56] provide a QFD model to study leanness of the food supply chain, and realizes the improvement of the lean level of the chain by means of identifying optimal LEs for implementation of food supply chain management through linking Lean Attributes (LAs) and Lean Enablers (LEs). Lam [57] has developed a framework that combines QFD with the Analytical Network Process (ANP) to design a sustainable maritime supply chain and considers customer-centric measures to achieve supply chain sustainability performance. Based on QFD thoughts, BuyukoZkan and Berkol [58] systematically connect the requirements of material and service processes among suppliers, manufacturers and customers with the design requirements of a sustainable supply chain. Focusing on resilient supply chains, Chowdhury and Quaddus [59] (2015) construct an interactive 0-1 multi-objective optimization model based on the QFD method to select the optimal supply chain flexibility strategy combination. He et al. [60] (2020) hold the view that a sustainable supply chain needs to achieve the improvement of elasticity. Therefore, the author builds a framework combining nonlinear programming and QFD to optimize the optimal elastic combination of risk mitigation at a minimum cost. Furthermore, a hybrid method based on DEMATEL and QFD is proposed to comprehensively select sustainability and elastic factors suitable for measuring and evaluating supply chain performance [61]. In the context of defining green supply chain standards based on QFD, Haiyun [62] combine the fuzzy DEMATEL and fuzzy multi-objective optimization model to obtain the ranking of green supply chain innovation strategies. Moreover, Prasad and Subbaiah [63] match the competitive strategy with the supply chain strategy in a supply chain design based on QFD.

\subsection{Research Gap}

The above literature review reveals that the shipbuilding supply chain is faced with diversified risks and uncertainties. Effective supply chain management to mitigate risks or deal with uncertainties is an inevitable choice for shipbuilding enterprises. However, most of the existing literature focuses on analyzing and assessing risks and formulating corresponding risk mitigation strategies, and there is a lack of systematic management and design of the shipbuilding supply chain. Actually, the utilization of multiple management techniques to implement supply chain processes is of great significance given that supply chain management is an integrated management concept. Therefore, what measures and methods should be taken to comprehensively manage the supply chain is worth exploring. Considering that flexibility is a powerful tool to deal with uncertainty effectively, as well as systematic and comprehensive research achievements being formed in this regard, this paper attempts to integrate flexible strategies into the supply chain design of shipbuilding materials organically to cope with possible risks in the supply process of shipbuilding materials by increasing flexibility of the supply chain.

In addition, from a detailed application analysis of QFD in supply chain management and design, it can be seen that QFD is widely utilized in designing lean, sustainable and green supply chains and has been proved to have universal applicability. However, it is seldom regarded as a tool to improve supply chain flexibility. In view of this, this paper makes an effort to construct a reasonable framework based on the QFD method to realize the supply chain design of shipbuilding materials, incorporating the flexible dimension. 


\section{A Hybrid Fuzzy DEMATEL-QFD Methodology}

\subsection{Research Process}

This paper mainly employs a hybrid method of fuzzy numbers, Decision-making Trial and Evaluation Laboratory (DEMATEL) and Quality Function Deployment (QFD) to design a supply chain with flexible characteristics. QFD is a customer-oriented design method, which can effectively transform customer needs into technical parameters in product design. In other words, QFD is from the perspective of customer needs, transforming the needs into the product development and design process, in which factors such as the market environment, user needs, and corporate competition are taken into consideration. Given the function and practicality of QFD, it has the ability to link CRS and DRS in the supply chain of shipbuilding materials, and is suitable for designing such a supply chain. The most basic and important part of QFD is to establish House of Quality (HOQ), which contains three key parts, namely identifying customer requirements (CRs) and obtaining their weights, identifying design requirements (DRs) and their interrelationships, as well as clarifying the relationship between CRs and DRs. AHP and ANP methods are currently well employed to determine weights of CRs or identify the correlation between DRs, but AHP is restricted in considering the internal relationship between factors. ANP can solve this problem but considers the correlation to be symmetric. However, the autocorrelation between CRs and DRs is asymmetrical regarding practical application. For this reason, this paper introduces the DEMATEL method, which can intuitively express the relationship between various factors and the causal influence. Furthermore, for reasons of inaccuracy and ambiguity are easily involved in describing relationships within factors, it is difficult to directly define. In order to overcome this limitation, fuzzy numbers with a good ability to deal with this situation are utilized. In practice, the proposed method can be summarized into the following five steps, and the constructed HOQ is denoted in Figure 1.

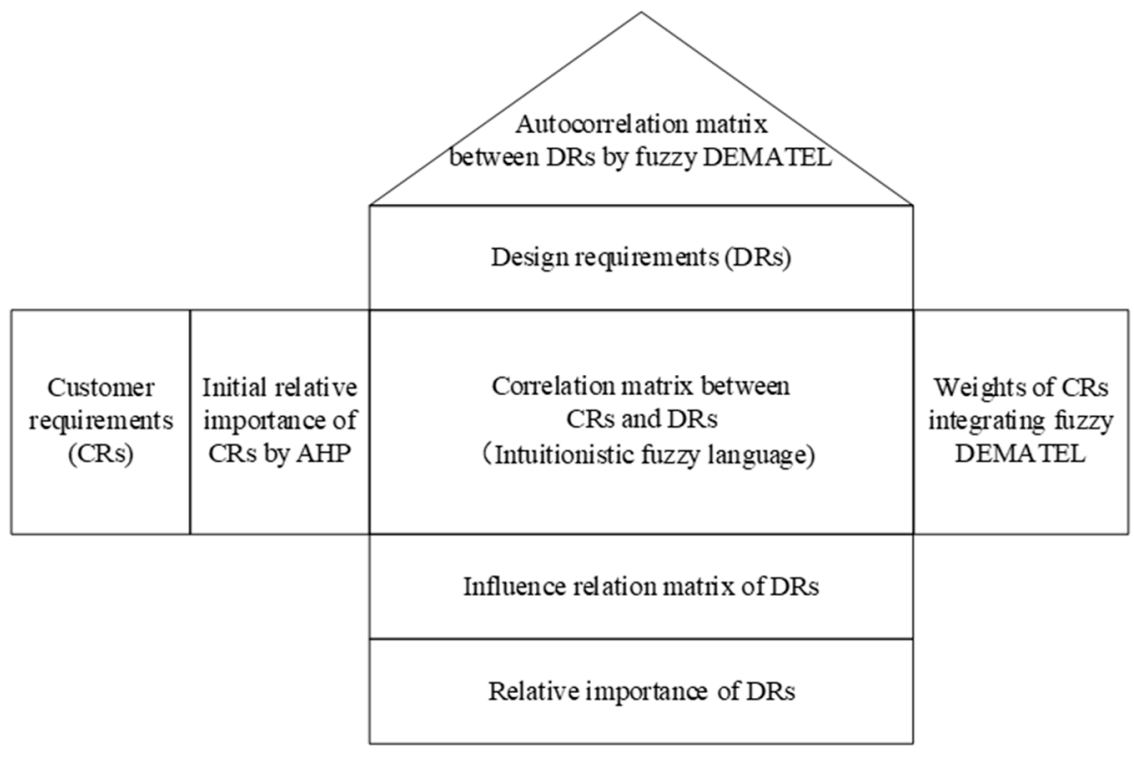

Figure 1. HOQ based on the fuzzy DEMATEL method.

Step 1: Identifying CRs by understanding the actual demand of supply chain of shipbuilding materials through inquiry, investigation, etc., and identifying DRs by investigating the measures taken by a shipbuilding company in response to the material supply demand and combining the aforementioned supply chain flexibility strategies.

Step 2: Without considering the internal connection of CRs, the analytic hierarchy process (AHP) is used to make pairwise comparisons to obtain the initial relative importance $\omega$ of CRs.

Step 3: Defining relations between CRs and DRs by intuitionistic fuzzy language to obtain the correlation matrix $W_{1}$. 
Step 4: Utilizing intuitionistic fuzzy DEMATEL to obtain the autocorrelation matrices $W_{2}$ and $W_{3}$ of CRs and DRs, respectively, by taking the relationship between factors into account.

Step 5: Achieving weights of CRs and calculating the ranking matrix of the influence relation of DRs, so as to clarify the relative importance of DRs for the realization of CRs.

\subsection{Identifying $C R s$ and $D R s$}

More specifically, the identification of CRs and DRs is divided into two stages. The first step is to obtain an initial list of CRs and DRs through the literature review, and the second step is to interview five employees of Shanghai Waigaoqiao Shipbuilding Co., Ltd. (SWS) to determine the appropriate CRs and DRs. These five employees are from the company's distribution department, procurement department, quality assurance department, including two department directors. They are mainly responsible for material procurement, planning, quality inspection, etc., and have 10 years or more of work experience in this industry. As a result, they can provide information related to the research.

\subsubsection{Supply Chain Demand Analysis for Shipbuilding Materials}

From a standpoint of shipbuilding, the most critical part lies in procurement, supply and distribution of materials needed to ensure the smooth construction of ships in accordance with the time node according to the opinions of the employees interviewed. However, large quantities and complicated types of materials in the shipbuilding industry as well as a high degree of customization of parts have resulted in a wide distribution of suppliers and a complex logistics environment, which inevitably leads to various risks in the supply chain and increases the difficulty in supply and distribution of shipbuilding materials. For most construction projects, a variety of risks will ultimately exert a negative impact on project goals such as time, cost and quality [64]. Additionally, the same is true for the shipbuilding industry. Sundara [65] describes the core concerns of shipbuilding companies as three components, each of which is the cost, quality, and construction time of the ship. The author also notes that multifarious unpredictability in the supply chain of shipbuilding materials would lead to project delays and cost overruns. In conclusion, in a supply chain of shipbuilding materials with shipbuilding enterprises as the core, increasing attention to the quality, supply and delivery of construction materials is a necessary prerequisite to ensure the smooth construction of ships and the normal completion of orders. In this regard, the identified CRs based on the perspective of shipbuilding materials are illustrated in Table 2.

Table 2. CRs for supply chain of shipbuilding materials.

\begin{tabular}{cc}
\hline Notations & Customer Requirements (CRs) \\
\hline CR1 & Quantity and quality assurance of materials \\
CR2 & Delivery reliability \\
CR3 & Timeliness of response to changes in demand \\
CR4 & Punctuality of arrival \\
CR5 & Cost control \\
\hline
\end{tabular}

\subsubsection{Supply Chain Design Requirements for Shipbuilding Materials}

From a perspective of shipbuilding enterprises, the provided delivery time, response capacity and material quality of upstream suppliers, the delivery capacity of logistics service providers, as well as the urgent order or order error caused by design changes of the enterprise itself, have a considerable impact on on-time construction of ships directly or indirectly. Therefore, shipbuilding enterprises will pay special attention to these aspects. Combining the aforementioned literature on shipbuilding supply chain risks to summarize and analyze, most believe that current main problems are in material supply and quality, information flow, demand planning, and coordination of various participants. Then, it is practical and effective to design corresponding flexible strategies from aspects of supply, 
information, logistics, and organization management to mitigate risks in a shipbuilding material supply chain. In order to ensure the timely and accurate supply of materials, shipbuilding companies can not only make flexible supply contracts with suppliers regarding the delivery time, but also sign agreements to guarantee the delivery of materials within the specified time and stipulate their responsibilities in case the task cannot be fulfilled. In addition, cooperating with suppliers to establish long-term good relationships and increase local procurement rates are also beneficial means to ensure the reliability of material supply. When it comes to logistics flexibility, it can be analyzed in terms of transportation mode, route, and inventory. Organizational flexibility refers to the integration of shipbuilding enterprises and supply chain members, and also includes some management mechanisms. In addition, increasing the degree of information sharing among supply chain members and using information technology are also conducive to the overall management of the supply chain. In the previous literature on supply chain flexibility, corresponding flexibility strategies have been listed from aspects of supply, logistics and organization, etc. Combined with actual demand characteristics of shipbuilding materials that require high quality, this paper introduces the flexibility strategy from a quality aspect. The details are elaborated in Table 3.

Table 3. DRs for a supply chain with flexibility.

\begin{tabular}{|c|c|c|}
\hline Flexible Aspects & Flexible Strategies & Source \\
\hline \multirow{9}{*}{ Supply flexibility DR1 } & Collaboration among supply chain members DR11 & [34] \\
\hline & Long-term strategic partnership with suppliers DR12 & {$[6,35]$} \\
\hline & A major supplier and substitutes in times of crisis DR13 & [37] \\
\hline & $\begin{array}{l}\text { New supplier selection based on multiple supplier } \\
\text { strategy DR14 }\end{array}$ & [38] \\
\hline & $\begin{array}{c}\text { Changeover among various suppliers regarding price, } \\
\text { production and quality DR15 }\end{array}$ & [17] \\
\hline & Domestic procurement DR16 & {$[18,39]$} \\
\hline & $\begin{array}{c}\text { flexible supply contracts regarding supply periods and } \\
\text { delivery schedules DR17 }\end{array}$ & {$[6]$} \\
\hline & Flexible price fluctuations in the contract DR18 & [37] \\
\hline & Supplier obligations are stipulated in the contract DR19 & [18] \\
\hline \multirow{5}{*}{ Logistics flexibility DR2 } & Strategic logistics outsourcing DR21 & {$[33,44]$} \\
\hline & $\begin{array}{l}\text { Alternative transportation modes and routes } \\
\text { under crisis DR22 }\end{array}$ & {$[36,44]$} \\
\hline & $\begin{array}{l}\text { Use tracking technology to increase transportation } \\
\text { transparency DR23 }\end{array}$ & [45] \\
\hline & Inventory buffers in response to increased demand DR24 & [47] \\
\hline & $\begin{array}{l}\text { Maintaining excess capacity in storage, handling and } \\
\text { transport DR25 }\end{array}$ & [18] \\
\hline \multirow{7}{*}{$\begin{array}{l}\text { Organizational/ } \\
\text { management flexibility DR3 }\end{array}$} & $\begin{array}{c}\text { Integration of various departments within } \\
\text { the company DR31 }\end{array}$ & [39] \\
\hline & Vertical integration of the supply chain DR32 & [18] \\
\hline & Labor training DR33 & [6] \\
\hline & $\begin{array}{c}\text { Emergency response mechanism for unexpected } \\
\text { accidents DR34 }\end{array}$ & [6] \\
\hline & Teamwork towards problems DR35 & [48] \\
\hline & Information sharing among supply chain members DR36 & {$[40,41]$} \\
\hline & $\begin{array}{l}\text { Company internal communication based on information } \\
\text { system DR37 }\end{array}$ & [41] \\
\hline \multirow{3}{*}{ Quality flexibility DR4 } & Strict quality inspection and management process DR41 & [48] \\
\hline & $\begin{array}{l}\text { Sampling inspection of special materials is allowed in the } \\
\text { factory DR42 }\end{array}$ & [48] \\
\hline & The quality is stipulated in the contract DR43 & [48] \\
\hline
\end{tabular}

\subsection{Fuzzy DEMATEL to Determine Weights of CRs and Prioritize DRs}

\subsubsection{Intuitionistic Fuzzy Numbers}

The concept of intuitionistic fuzzy numbers, first proposed by the scholar Atanassov, is an extension of conventional fuzzy numbers. Compared with the traditional fuzzy number which only considers the membership degree, it is more flexible to deal with uncertain information by introducing the concepts of non-membership degree and hesitation degree. 
When making decisions in the real world, for example, defining the relationship between things inevitably contains uncertainty and ambiguity, and there are also problems that are difficult to quantify directly. Intuitionistic fuzzy numbers can fully reflect uncertainties of the decision-making environment with the help of rich language description terms, which is very suitable for such a situation. In view of this, intuitionistic fuzzy numbers are employed to transform language descriptions into exact values, so as to finally prioritize DRs.

Let $\widetilde{\alpha}=\left(\mu_{\widetilde{\alpha}}, v_{\widetilde{\alpha}}\right)$ be an intuitionistic number. Then, $\mu_{\widetilde{\alpha}}$ and $v_{\widetilde{\alpha}}$ represent the degree of membership and non-membership of $x$ respectively. Additionally, if $\widetilde{\alpha}=\left(\mu_{\widetilde{\alpha}}, v_{\tilde{\alpha}}\right)$, $\widetilde{\alpha}_{1}=\left(\mu_{\widetilde{\alpha}_{1}}, v_{\widetilde{\alpha}_{1}}\right)$ and $\widetilde{\alpha}_{2}=\left(\mu_{\widetilde{\alpha}_{2}}, v_{\widetilde{\alpha}_{2}}\right)$ are three intuitionistic fuzzy numbers and $\lambda$ is a real number, the following are three corresponding arithmetical operations:

$$
\begin{gathered}
\widetilde{\alpha}_{1} \oplus \widetilde{\alpha}_{2}=\left(\mu_{\widetilde{\alpha}_{1}}+\mu_{\widetilde{\alpha}_{2}}-\mu_{\widetilde{\alpha}_{1}} \mu_{\widetilde{\alpha}_{2}}, v_{\widetilde{\alpha}_{1}} v_{\widetilde{\alpha}_{2}}\right) \\
\widetilde{\alpha}_{1} \otimes \widetilde{\alpha}_{2}=\left(\mu_{\widetilde{\alpha}_{1}} \mu_{\widetilde{\alpha}_{2}}, v_{\widetilde{\alpha}_{1}}+v_{\widetilde{\alpha}_{2}}-v_{\widetilde{\alpha}_{1}} v_{\widetilde{\alpha}_{2}}\right) \\
\lambda \widetilde{\alpha}=\left(1-\left(1-\mu_{\widetilde{\alpha}}\right)^{\lambda}, v_{\widetilde{\alpha}}^{\lambda}\right), \lambda>0
\end{gathered}
$$

Besides, if $\widetilde{\alpha}_{i}=\left(\mu_{\widetilde{\alpha}_{i}}, v_{\widetilde{\alpha}_{i}}\right),(i=1,2, \cdots, n)$ represent $n$ intuitionistic fuzzy numbers, thus the following arithmetical operation can aggregate these fuzzy numbers.

$$
\operatorname{IFWA}_{\omega}\left(\widetilde{\alpha}_{1}, \widetilde{\alpha}_{2}, \cdots, \widetilde{\alpha}_{n}\right)=\omega_{1} \widetilde{\alpha}_{1} \oplus \omega_{2} \widetilde{\alpha}_{2} \oplus \cdots \oplus \omega_{n} \widetilde{\alpha}_{n}
$$

where IFWA operator denotes the intuitionistic fuzzy weighted average operator, $\omega=\left(\omega_{1}, \omega_{2}, \cdots, \omega_{n}\right)^{T}$ is the weight vector of $\widetilde{\alpha}_{i}=\left(\mu_{\widetilde{\alpha}_{i}}, v_{\widetilde{\alpha}_{i}}\right)(i=1,2, \cdots, n)$.

Moreover, we can define the score value $\mathrm{I}(\widetilde{\alpha})$ of $\widetilde{\alpha}$ by the following operation [66]:

$$
\mathrm{I}(\widetilde{\alpha})=\frac{\exp \left\{\mu_{\widetilde{\alpha}}-v_{\widetilde{\alpha}}+\left(\mu_{\widetilde{\alpha}}-v_{\widetilde{\alpha}}\right)^{3} \pi_{\widetilde{\alpha}}\right\}}{1+\pi_{\widetilde{\alpha}}}
$$

where $\pi_{\widetilde{\alpha}}=1-\mu_{\widetilde{\alpha}}-v_{\widetilde{\alpha}}$ represents the hesitation of $x$.

\subsubsection{Obtaining Initial Weight $\omega$ of CRs}

Analytic hierarchy process (AHP), as a simple and practical decision-making method combining qualitative and quantitative analysis, was first proposed by American scholar Saaty for hierarchical weight decision analysis. AHP can not only decompose complex systems, but also express people's subjective judgments in a mathematical and quantitative form. That is to say, the knowledge and experience of decision-makers can be fully utilized in a decision-making process. The calculation process of AHP is divided into three stages, namely, establishment of the hierarchical structure model, construction of the judgment matrix and the consistency test, in which the judgment matrix is obtained by pairwise comparison using a nine-point scale. In general, AHP is often regarded as an auxiliary tool to determine weights and is integrated with other methods to solve practical problems, such as its widespread use in QFD methods. Since the internal influence of factors is excluded by $\mathrm{AHP}$, this paper only employs it to determine the initial weight of CRs and then combines the fuzzy DEMATEL method. After determining CRs, a pairwise comparison of five factors is made with respect to the goal of shipbuilding enterprises. Thus, a judgment matrix is prepared after the evaluation results of decision-makers are quantified based on the nine-point scale. Moreover, the initial weight $\omega$ is achieved by calculation steps provided in AHP, which shows the extent to which these factors pose an influence on shipbuilding. In addition, it is necessary to calculate the consistency indicator and consistency ratio to conduct the consistency test to identify whether the matrix constructed based on DMs needs to be adjusted. 


\subsubsection{Obtaining Correlation Matrix $W_{1}$}

Determining the correlation between the five identified CRs and 24 DRs is crucial for implementing QFD. In order to describe such relationships more accurately, this paper designs a questionnaire based on the concept of intuitionistic fuzzy numbers to collect opinions of DMs with corresponding background knowledge on the importance of DRs in achieving CRs. In this step, the degree of correlation between CRs and DRs is expressed by linguistic variables, namely "strong correlation", "medium correlation" and "weak correlation", as denoted in Table 4 . When there is no correlation, 0 is used.

Table 4. Correlation degree between CRs and DRs and the corresponding fuzzy number.

\begin{tabular}{cc}
\hline Degree of Correlation & Intuitionistic Fuzzy Values \\
\hline Strong (S) & $(0.85,0.10)$ \\
Medium (M) & $(0.50,0.40)$ \\
Weak (W) & $(0.10,0.85)$ \\
\hline
\end{tabular}

\subsubsection{Obtaining Autocorrelation Matrix of CRs and DRs}

DEMATEL is a methodology aimed at solving complex and difficult problems in the real world. By clarifying the logical relationship and direct influence relationship among a variety of elements in a system, this method can judge the existence and strength of the relationship among these elements. We here utilize the fuzzy DEMATEL method to achieve the autocorrelation matrix, in which three DMs use language variables to evaluate the autocorrelation relationship of CRs and DRs, respectively, and then intuitionistic fuzzy numbers are employed to convert the subjective judgments into numerical values. In this step, the degree of relationship between factors is illustrated by corresponding intuitionistic fuzzy language variables, as shown in Table 5 , and the acquisition of autocorrelation matrix is divided into 5 steps.

Table 5. Degree of internal influence and the corresponding fuzzy number.

\begin{tabular}{cc}
\hline Degree of Influence & Intuitionistic Fuzzy Values \\
\hline Strong influence (SI) & $(0.85,0.10)$ \\
Moderate influence (MI) & $(0.50,0.40)$ \\
Weak influence (WI) & $(0.10,0.85)$ \\
\hline
\end{tabular}

Step 1: DMs evaluate the relationship between internal factors of CRs and DRs, respectively, and obtain corresponding two fuzzy initial direct relation matrices $M_{1 k}$ and $M_{2 k}$. Taking CRs evaluation as an example, let the matrix $M_{1 k}=\left(\widetilde{a}_{i j k}\right)_{5 \times 5}$, where $\widetilde{a}_{i j k}$ represents the impact of customer requirements $\mathrm{CR}_{i}$ on $\mathrm{CR}_{j}$ considered by decision maker $\mathrm{k}$.

Step 2: Aggregate the fuzzy initial direct relationship matrices, and obtain fuzzy aggregation matrices $M_{1}$ and $M_{2}$ according to Formula (1). Subsequently, Formula (2) is used for defuzzification, thus matrices $M_{1}$ and $M_{2}$ are transformed into real number matrices $Z_{1}$ and $Z_{2}$. Take matrices corresponding to CRs as an example, $M_{1}=\left(\widetilde{a}_{i j}\right)_{5 \times 5^{\prime}}$ $Z_{1}=\left(a_{i j}\right)_{5 \times 5}$, where $\widetilde{a}_{i j}$ and $a_{i j}$ are the fuzzy aggregation evaluation value and real value of the impact of $\mathrm{CR}_{i}$ on $\mathrm{CR}_{j}$, respectively.

Step 3: Normalize $Z_{1}$ and $Z_{2}$ through the following calculation to realize the normalized initial direct relationship matrix $N_{1}$ and $N_{2}$.

$$
N=\left(\frac{a_{i j}}{\max \left(\sum_{j=1}^{n} a_{i j}\right)}\right)_{n \times n}
$$


Step 4: Use the following calculation to solve the total relationship matrix $T_{1}$ and $T_{2}$.

$$
T=N \times(I-N)^{-1}=\left(b_{i j}\right)_{n \times n}
$$

Step 5: Calculate the standardized total relation matrix $W_{2}$ and $W_{3}$, and let $W=\left(b_{i j}{ }^{\prime}\right)_{n \times n}$.

$$
b_{i j}{ }^{\prime}=\frac{b_{i j}}{\sum_{i=1}^{n} b_{i j}}
$$

\subsubsection{Determining Priority Weight of DRs}

Based on the above calculation, according to the initial weight and autocorrelation matrix of CRs, the final weight $\omega^{\prime}$ can be realized. Accordingly, the ranking matrix $W$ of the influence relationship of DRs is calculated with respect to correlation matrix $W_{1}$ and autocorrelation matrix $W_{3}$. Finally, the relative importance $R I$ of DRs to achieve a flexible shipbuilding material supply chain is clarified.

$$
\begin{aligned}
& \omega^{\prime}=W_{2} \times \omega \\
& W=W_{3} \times W_{1} \\
& R I=W \times \omega^{\prime}
\end{aligned}
$$

\section{Results and Discussion}

\subsection{Case Study Results}

In this section, the proposed hybrid fuzzy DEMATEL-QFD framework is applied for practical calculation according to summarized steps in Section 3. For the weight decision involved in the AHP method and the influence relationship between CRs and DRs in the DEMATEL method, the three decision makers related in this paper are employees with more than 10 years of work experience from the distribution department of Shanghai Waigaoqiao Shipbuilding Co., Ltd. (SWS). The distribution department is responsible for centralization and inbound distribution of various materials used in shipbuilding and has a close working relationship with the procurement department, quality assurance department, and production department, which means that it can provide available and effective information for research in this regard. We collect the original qualitative data by designing questionnaires and transform them into quantitative values step by step by means of the proposed method, so as to obtain the final decision results.

The first step in applying this methodology is to refine the CRs and DRs in the supply chain of shipbuilding material with flexible characteristics. Based on the actual requirements of shipbuilding enterprises and the whole supply chain, there are 5 CRs and 24 DRs placed in HOQ. Next, step 2 assumes that there is no autocorrelation relationship between customer needs. Confronting to shipyard's goal, DMs employ AHP to obtain the pairwise comparison matrix of CRs. After calculation and consistency check, the initial weights of CRs are CR1 $=0.344$, CR2 $=0.192, C R 3=0.193, C R 4=0.160, C R 5=0.111$. As showed in this result, the most critical regard for shipbuilding enterprises is to ensure the quantity and quality of materials as the initial weight of CR1 is obviously prominent.

Step 3 of the proposed comprehensive method deals with the evaluation information of DMs on the correlation between CRs and DRs abiding by the relationship between linguistic variables and intuitionistic fuzzy numbers in Table 4 , thereby obtaining the corresponding fuzzy correlation matrix. In Formulas (1) and (2), matrix aggregation and defuzzification are performed, respectively, to acquire the final real number correlation matrix $W_{1}$ between CRs and DRs, as shown in Table 6 . 
Table 6. Real number correlation matrix between CRs and DRs.

\begin{tabular}{lccccccccccc}
\hline & CR1 & CR2 & CR3 & CR4 & CR5 & & CR1 & CR2 & CR3 & CR4 & CR5 \\
\hline DR11 & 1.767 & 1.767 & 1.767 & 1.767 & 1.404 & DR24 & 1.404 & 1.000 & 1.767 & 1.000 & 2.059 \\
DR12 & 2.059 & 1.005 & 1.767 & 1.361 & 0.554 & DR25 & 0.917 & 1.404 & 1.005 & 0.809 & 1.404 \\
DR13 & 2.059 & 0.554 & 2.059 & 0.809 & 1.210 & DR31 & 0.690 & 0.527 & 0.722 & 1.000 & 0.722 \\
DR14 & 0.440 & 0.440 & 0.618 & 0.722 & 0.722 & DR32 & 1.102 & 2.059 & 1.595 & 1.404 & 1.595 \\
DR15 & 1.767 & 0.722 & 1.102 & 0.554 & 1.767 & DR33 & 0.809 & 1.000 & 0.690 & 1.000 & 0.722 \\
DR16 & 1.404 & 1.767 & 1.210 & 1.005 & 1.361 & DR34 & 2.059 & 1.005 & 2.059 & 0.722 & 1.774 \\
DR17 & 1.595 & 1.013 & 0.690 & 0.722 & 0.917 & DR35 & 1.102 & 1.102 & 1.404 & 1.102 & 1.102 \\
DR18 & 1.141 & 1.000 & 1.000 & 0.690 & 1.404 & DR36 & 1.361 & 1.404 & 1.774 & 1.141 & 0.722 \\
DR19 & 1.210 & 0.618 & 0.917 & 0.722 & 1.404 & DR37 & 0.690 & 1.000 & 1.361 & 0.722 & 0.690 \\
DR21 & 0.722 & 1.210 & 0.554 & 1.404 & 1.361 & DR41 & 2.059 & 1.000 & 1.000 & 1.000 & 2.059 \\
DR22 & 1.005 & 2.059 & 1.005 & 1.005 & 1.595 & DR42 & 1.404 & 1.000 & 1.000 & 1.000 & 1.210 \\
DR23 & 0.527 & 1.404 & 0.527 & 0.809 & 0.527 & DR43 & 1.404 & 1.000 & 0.527 & 1.000 & 1.404 \\
\hline
\end{tabular}

Considering the autocorrelation of CRs and DRs, respectively, DMs perform a semantic evaluation on this relationship based on the definition in Table 5 in Step 4 to realize the fuzzy initial direct relationship matrix. Relying on Formulas (1) and (2) to calculate the group decision value, in which evaluation results are processed according to the intuitionistic fuzzy number, and the intuitionistic fuzzy average (IFA) operator is utilized to aggregate the results assuming DMs shows equal weight. Thus, an initial direct relationship matrix is demonstrated in Table 7 (taking CRs as an example). Furthermore, by means of Equations (3)-(5), the initial normalized direct relation matrix and the total relation matrix are successively solved, thus the normalized autocorrelation matrices $W_{2}$ and $W_{3}$ are, respectively, stated in Tables 8 and 9 .

Table 7. Initial direct relationship matrix of CRs.

\begin{tabular}{lccccc}
\hline & CR1 & CR2 & CR3 & CR4 & CR5 \\
\hline CR1 & 0.000 & 0.000 & 1.102 & 0.527 & 1.767 \\
CR2 & 1.005 & 0.000 & 0.917 & 1.361 & 0.722 \\
CR3 & 1.404 & 0.554 & 0.000 & 2.059 & 0.690 \\
CR4 & 0.527 & 0.000 & 0.690 & 0.000 & 1.404 \\
CR5 & 0.000 & 0.527 & 1.005 & 0.000 & 0.000 \\
\hline
\end{tabular}

Table 8. Normalized autocorrelation matrix $W_{2}$ of CRs.

\begin{tabular}{llllll}
\hline & CR1 & CR2 & CR3 & CR4 & CR5 \\
\hline CR1 & 0.133 & 0.170 & 0.229 & 0.179 & 0.247 \\
CR2 & 0.278 & 0.168 & 0.246 & 0.277 & 0.226 \\
CR3 & 0.330 & 0.307 & 0.194 & 0.339 & 0.251 \\
CR4 & 0.158 & 0.131 & 0.167 & 0.101 & 0.197 \\
CR5 & 0.101 & 0.224 & 0.163 & 0.103 & 0.079 \\
\hline
\end{tabular}

Step 5 is to multiply the initial weight of CRs and its autocorrelation matrix, and achieve the final weight $\omega^{\prime}$ of CRs with the help of Formula (6), where CR1 $=0.179$, $\mathrm{CR} 2=0.245, \mathrm{CR} 3=0.292, \mathrm{CR} 4=0.150, \mathrm{CR} 5=0.135$. Compared with the initial weight $\omega$, it can be clearly observed that the weight of CR1 is reduced, while the weights of CR2 and CR3 are both increased. This is mainly because the regulating effect of the autocorrelation matrix considering CR2 (delivery reliability) and CR3 (timeliness of response to changes in demand) has a greater impact on other factors such as the punctual arrival of materials and quantity guarantee. Next, the ranking matrix $W$ of the influence relationship of DRs is obtained by multiplying correlation matrix $W_{1}$ and standardized autocorrelation matrix $W_{3}$ by means of Formula (7), which is detailed in Table 10. Finally, the relative importance RI of DRs is clarified by Formula (8), as elaborated in Table 11. 
Table 9. Normalized autocorrelation matrix $W_{3}$ of DRs.

\begin{tabular}{|c|c|c|c|c|c|c|c|c|c|c|c|c|}
\hline & DR11 & DR12 & DR13 & DR14 & DR15 & DR16 & DR17 & DR18 & DR19 & DR21 & DR22 & DR23 \\
\hline DR11 & 0.042 & 0.074 & 0.064 & 0.061 & 52 & 0.043 & 0.069 & 0.075 & 0.058 & 0.052 & 0.064 & .072 \\
\hline DR12 & 0.063 & 0.043 & 0.081 & 0.061 & 0.065 & 0.044 & 0.079 & 0.083 & 0.061 & 0.053 & 0.051 & 0.056 \\
\hline DR13 & 0.045 & 0.062 & 0.031 & 0.071 & 0.068 & 0.039 & 0.064 & 0.070 & 0.046 & 0.046 & 0.045 & 0.044 \\
\hline DR14 & 0.040 & 0.036 & 0.022 & 0.022 & 0.048 & 0.026 & 0.040 & 0.022 & 0.038 & 0.041 & 0.037 & 0.023 \\
\hline DR15 & 0.065 & 0.071 & 0.036 & 0.068 & 0.037 & 0.128 & 0.076 & 0.080 & 0.049 & 0.049 & 0.049 & 0.053 \\
\hline DR16 & 0.074 & 0.065 & 0.080 & 0.083 & 0.083 & 0.049 & 0.085 & 0.082 & 0.062 & 0.068 & 0.069 & 0.076 \\
\hline DR17 & 0.044 & 0.056 & 0.029 & 0.058 & 0.053 & 0.086 & 0.029 & 0.061 & 0.049 & 0.042 & 0.049 & 0.045 \\
\hline DR18 & 0.031 & 0.037 & 0.020 & 0.051 & 0.045 & 0.026 & 0.032 & 0.021 & 0.030 & 0.019 & 0.032 & 0.020 \\
\hline DR19 & 0.033 & 0.036 & 0.020 & 0.020 & 0.019 & 0.063 & 0.034 & 0.034 & 0.017 & 0.028 & 0.019 & 0.035 \\
\hline DR21 & 0.054 & 0.043 & 0.032 & 0.047 & 0.028 & 0.032 & 0.053 & 0.042 & 0.052 & 0.030 & 0.063 & 0.071 \\
\hline DR22 & 0.040 & 0.030 & 0.039 & 0.019 & 0.017 & 0.021 & 0.018 & 0.017 & 0.016 & 0.039 & 0.032 & 0.047 \\
\hline DR23 & 0.044 & 0.022 & 0.026 & 0.021 & 0.021 & 0.022 & 0.019 & 0.021 & 0.020 & 0.023 & 0.043 & 0.024 \\
\hline DR24 & 0.039 & 0.038 & 0.061 & 0.046 & 0.050 & 0.035 & 0.050 & 0.044 & 0.037 & 0.033 & 0.042 & 0.040 \\
\hline DR25 & 0.029 & 0.016 & 0.041 & 0.017 & 0.015 & 0.019 & 0.030 & 0.015 & 0.013 & 0.029 & 0.048 & 0.018 \\
\hline DR31 & 0.037 & 0.026 & 0.048 & 0.024 & 0.024 & 0.025 & 0.038 & 0.025 & 0.041 & 0.049 & 0.034 & 0.027 \\
\hline DR32 & 0.083 & 0.075 & 0.075 & 0.060 & 0.063 & 0.043 & 0.064 & 0.043 & 0.062 & 0.075 & 0.065 & 0.075 \\
\hline DR33 & 0.019 & 0.019 & 0.036 & 0.037 & 0.034 & 0.024 & 0.029 & 0.019 & 0.034 & 0.034 & 0.029 & 0.035 \\
\hline DR34 & 0.048 & 0.051 & 0.087 & 0.081 & 0.071 & 0.145 & 0.050 & 0.053 & 0.053 & 0.053 & 0.067 & 0.054 \\
\hline DR35 & 0.045 & 0.048 & 0.045 & 0.046 & 0.026 & 0.027 & 0.025 & 0.043 & 0.026 & 0.049 & 0.046 & 0.053 \\
\hline DR36 & 0.074 & 0.060 & 0.033 & 0.057 & 0.055 & 0.034 & 0.034 & 0.062 & 0.055 & 0.054 & 0.052 & 0.065 \\
\hline DR37 & 0.018 & 0.035 & 0.040 & 0.019 & 0.041 & 0.023 & 0.018 & 0.037 & 0.040 & 0.039 & 0.037 & 0.034 \\
\hline DR41 & 0.013 & 0.025 & 0.027 & 0.014 & 0.039 & 0.019 & 0.031 & 0.029 & 0.053 & 0.034 & 0.012 & 0.013 \\
\hline DR42 & 0.007 & 0.007 & 0.004 & 0.006 & 0.020 & 0.010 & 0.007 & 0.007 & 0.037 & 0.029 & 0.006 & 0.007 \\
\hline \multirow[t]{2}{*}{ DR43 } & 0.011 & 0.025 & 0.026 & 0.011 & 0.026 & 0.016 & 0.028 & 0.013 & 0.051 & 0.033 & 0.010 & 0.012 \\
\hline & L & D & DR31 & 2 & 3 & 4 & 5 & 6 & 7 & 1 & 12 & 43 \\
\hline DR11 & 0.080 & 0.072 & 0.033 & 0.087 & 0.042 & 0.066 & 0.069 & 0.077 & 0.032 & 0.063 & 0.089 & 0.121 \\
\hline DR12 & 0.064 & 0.040 & 0.029 & 0.089 & 0.043 & 0.057 & 0.074 & 0.077 & 0.031 & 0.064 & 0.093 & 0.145 \\
\hline DR13 & 0.052 & 0.063 & 0.024 & 0.071 & 0.033 & 0.049 & 0.051 & 0.052 & 0.025 & 0.031 & 0.037 & 0.034 \\
\hline DR14 & 0.044 & 0.022 & 0.017 & 0.059 & 0.021 & 0.032 & 0.021 & 0.023 & 0.015 & 0.048 & 0.073 & 0.106 \\
\hline DR15 & 0.040 & 0.037 & 0.032 & 0.072 & 0.037 & 0.055 & 0.066 & 0.068 & 0.030 & 0.062 & 0.091 & 0.045 \\
\hline DR16 & 0.071 & 0.081 & 0.129 & 0.084 & 0.046 & 0.062 & 0.074 & 0.072 & 0.041 & 0.044 & 0.097 & 0.155 \\
\hline DR17 & 0.062 & 0.062 & 0.026 & 0.030 & 0.021 & 0.040 & 0.046 & 0.042 & 0.127 & 0.055 & 0.030 & 0.034 \\
\hline DR18 & 0.058 & 0.050 & 0.011 & 0.021 & 0.015 & 0.037 & 0.037 & 0.036 & 0.012 & 0.018 & 0.022 & 0.022 \\
\hline DR19 & 0.056 & 0.021 & 0.018 & 0.019 & 0.015 & 0.035 & 0.036 & 0.033 & 0.016 & 0.045 & 0.018 & 0.020 \\
\hline DR21 & 0.052 & 0.096 & 0.145 & 0.055 & 0.031 & 0.052 & 0.045 & 0.061 & 0.034 & 0.067 & 0.028 & 0.028 \\
\hline DR22 & 0.042 & 0.060 & 0.022 & 0.018 & 0.010 & 0.045 & 0.018 & 0.018 & 0.015 & 0.016 & 0.015 & 0.018 \\
\hline DR23 & 0.044 & 0.071 & 0.132 & 0.041 & & & & 0.057 & 0.126 & 0.048 & 0.021 & 0.017 \\
\hline DR24 & 0.026 & 0.069 & 0.020 & 0.024 & 0.013 & 0.055 & 0.025 & 0.023 & 0.020 & 0.022 & 0.022 & 0.024 \\
\hline DR25 & 0.039 & 0.020 & 0.013 & 0.014 & 0.012 & 0.037 & 0.032 & 0.013 & 0.011 & 0.012 & 0.013 & 0.013 \\
\hline DR31 & 0.022 & 0.023 & 0.023 & 0.042 & 0.153 & 0.040 & 0.070 & 0.043 & 0.195 & 0.118 & 0.023 & 0.017 \\
\hline DR32 & 0.043 & 0.043 & 0.043 & & 0.195 & & 0.076 & 0.091 & 0.036 & 0.042 & 0.106 & 0.043 \\
\hline DR33 & 0.018 & 0.018 & 0.137 & 0.019 & 0.019 & 0.036 & 0.037 & 0.037 & 0.130 & 0.049 & 0.017 & 0.014 \\
\hline DR34 & 0.035 & 0.037 & 0.034 & 0.037 & 0.024 & 0.033 & 0.050 & 0.034 & 0.024 & 0.031 & 0.037 & 0.040 \\
\hline DR35 & 0.027 & 0.027 & 0.030 & 0.053 & 0.183 & 0.052 & 0.025 & 0.057 & 0.022 & 0.052 & 0.090 & 0.027 \\
\hline DR36 & 0.072 & 0.036 & 0.031 & 0.072 & 0.028 & 0.050 & 0.033 & 0.035 & 0.023 & 0.059 & 0.036 & 0.037 \\
\hline DR37 & 0.018 & 0.020 & 0.019 & 0.018 & 0.014 & 0.032 & 0.032 & 0.019 & 0.012 & 0.017 & 0.017 & 0.015 \\
\hline DR41 & 0.015 & 0.014 & 0.013 & 0.013 & 0.007 & 0.013 & 0.014 & 0.014 & 0.010 & 0.015 & 0.012 & 0.011 \\
\hline DR42 & 0.007 & 0.007 & 0.009 & 0.006 & 0.004 & 0.006 & 0.007 & 0.007 & 0.004 & 0.008 & 0.005 & 0.004 \\
\hline DR43 & 0.013 & 0.012 & 0.012 & 0.011 & 0.006 & 0.011 & 0.012 & 0.012 & 0.009 & 0.013 & 0.010 & 0.010 \\
\hline
\end{tabular}


Table 10. Ranking matrix $W$ of the influence relationship of DRs.

\begin{tabular}{lccccccccccc}
\hline & CR1 & CR2 & CR3 & CR4 & CR5 & & CR1 & CR2 & CR3 & CR4 & CR5 \\
\hline DR11 & 2.040 & 1.779 & 1.827 & 1.526 & 1.973 & DR24 & 1.139 & 0.958 & 1.032 & 0.804 & 1.085 \\
DR12 & 2.054 & 1.740 & 1.799 & 1.517 & 1.976 & DR25 & 0.694 & 0.609 & 0.656 & 0.514 & 0.682 \\
DR13 & 1.477 & 1.320 & 1.363 & 1.121 & 1.442 & DR31 & 1.421 & 1.285 & 1.372 & 1.126 & 1.365 \\
DR14 & 1.190 & 1.009 & 0.987 & 0.884 & 1.172 & DR32 & 2.031 & 1.802 & 1.855 & 1.611 & 1.866 \\
DR15 & 1.833 & 1.655 & 1.648 & 1.394 & 1.725 & DR33 & 1.010 & 0.887 & 1.001 & 0.820 & 0.980 \\
DR16 & 2.317 & 2.017 & 2.060 & 1.792 & 2.252 & DR34 & 1.597 & 1.416 & 1.439 & 1.183 & 1.530 \\
DR17 & 1.463 & 1.343 & 1.407 & 1.117 & 1.453 & DR35 & 1.392 & 1.275 & 1.268 & 1.130 & 1.309 \\
DR18 & 0.923 & 0.788 & 0.862 & 0.677 & 0.905 & DR36 & 1.494 & 1.335 & 1.372 & 1.155 & 1.486 \\
DR19 & 0.932 & 0.807 & 0.847 & 0.687 & 0.891 & DR37 & 0.803 & 0.680 & 0.729 & 0.587 & 0.772 \\
DR21 & 1.506 & 1.396 & 1.413 & 1.214 & 1.499 & DR41 & 0.615 & 0.480 & 0.527 & 0.432 & 0.586 \\
DR22 & 0.813 & 0.743 & 0.777 & 0.627 & 0.804 & DR42 & 0.274 & 0.232 & 0.235 & 0.212 & 0.290 \\
DR23 & 1.151 & 1.095 & 1.192 & 0.962 & 1.154 & DR43 & 0.528 & 0.411 & 0.454 & 0.377 & 0.495 \\
\hline
\end{tabular}

Table 11. Relative importance $R I$ of DRs.

\begin{tabular}{|c|c|c|c|c|c|c|c|c|c|c|c|c|}
\hline Criteria & DR11 & DR12 & DR13 & DR14 & DR15 & DR16 & DR17 & DR18 & DR19 & DR21 & DR22 & DR23 \\
\hline $\begin{array}{c}R I \\
\text { value }\end{array}$ & 1.828 & 1.812 & 1.347 & 1.038 & 1.655 & 2.081 & 1.364 & 0.833 & 0.834 & 1.407 & 0.756 & 1.121 \\
\hline Criteria & DR24 & DR25 & DR31 & DR32 & DR33 & DR34 & DR35 & DR36 & DR37 & DR41 & DR42 & DR43 \\
\hline $\begin{array}{c}R I \\
\text { value }\end{array}$ & 1.006 & 0.634 & 1.322 & 1.838 & 0.945 & 1.435 & 1.277 & 1.367 & 0.715 & 0.525 & 0.245 & 0.451 \\
\hline
\end{tabular}

As revealed in Table 11, the RI value of domestic procurement DR16 among 24 DRs is significantly higher than other indicators, which indicates it is absolutely essential for constructing a flexible supply chain of shipbuilding material. In addition, the remaining 10 indicators with relatively high RI values are DR11 (collaboration among supply chain members), DR32 (vertical integration of the supply chain), DR12 (long-term strategic partnership with suppliers), DR15 (changeover among various suppliers regarding price, production and quality), DR34 (emergency response mechanism for unexpected accidents), DR21 (strategic logistics outsourcing), DR36 (information sharing among supply chain members), DR17 (flexible supply contracts regarding supply periods and delivery schedules), DR13 (a major supplier and substitutes in times of crisis), and DR31 (integration of various departments within the company). From an overall perspective, the RI value of DRs in terms of supply flexibility is generally higher due to their high degree of closeness to realize shipbuilding enterprises' goals.

\subsection{Discussion}

Shipbuilding enterprises have been committed to reducing the uncertainties of the material transportation business in order to decrease the impact on ship construction. Increasing flexibility of the supply chain helps reduce uncertainties. Therefore, in order to build a flexible supply chain of shipbuilding materials, this paper adopts a systematic development and design tool QFD to make efforts to study how to design such a chain. Focusing on the specific needs of shipbuilding enterprises, five CRs are relatively important. Aiming to meet CRs as much as possible, this paper identifies 24 DRs from four aspects of supply, logistics, management/organization and quality flexibility. The most important design factors among which are domestic procurement (DR16), collaboration among supply chain members (DR11), vertical integration of the supply chain (DR32), and long-term strategic partnership with suppliers (DR12). The importance of DR16 is reflected in its significant contribution to all CRs implementations. In the context of domestic procurement of materials, shipbuilding enterprises can better cooperate with suppliers and get better guarantees in terms of the transport route, speed, and quantity of materials. Even if any problems are found, better responsiveness is provided. The remaining three design requirements reflect a common goal, i.e., mutual cooperation among members of the supply 
chain. One plausible explanation is cooperation can enhance the reliability of supplies and transport, thus better responding to CRs.

Besides, the relative important DRs are changeover among various suppliers regarding price, production and quality (DR15), emergency response mechanism for unexpected accidents (DR34), strategic logistics outsourcing (DR21), information sharing among supply chain members (DR36), flexible supply contracts regarding supply periods and delivery schedules (DR17), a major supplier and substitutes in times of crisis (DR13), integration of various departments within the company (DR31). The reasons for the high scores of DR15 and DR17 indicate that addressing supplier quality problems and defining their responsibilities is helpful to realize CRs. DR34 and DR13 state that emergency responses in the face of emergencies are of great value to flexible supply chain design, which may therefore cater well to CR1, CR3 and CR4. Moreover, DR21 is also considered to be relatively important, which reveals that logistics outsourcing under appropriate circumstances can improve the reliability of distribution, thereby ensuring timely delivery of materials. It is worth noting that DR36 and DR31 demonstrate demand for effective information sharing and collaboration across the supply chain as well as within the shipbuilding enterprises to availably improve work efficiency; thus, this is an issue that must be important.

The rigid construction period of ships puts forward high demand on the supply of shipbuilding materials. Any material failure in the chain can disrupt shipbuilding enterprises' production schedules and ultimately affect the ship's construction schedule and delivery time. However, the effectiveness of information transmission, plan change response, quality assurance and distribution activities in a shipbuilding supply chain with diverse participants is limited, which means that the supply chain needs to maintain great flexibility. Although some literature confirms this, there are few studies on the flexibility of the supply chain of shipbuilding materials by considering shipbuilding enterprises' requirements under uncertain environments. This paper analyzes flexible strategies of supply chain operation to satisfy demand fluctuation in supply, transportation and organization of shipbuilding materials as much as possible, so as to supplement flexible application work in this regard. Additionally, when it comes to the practical application of the method, the fuzzy DEMATEL-QFD model accurately links CRS with DRs, as well as emphasizes flexible strategies that realize the needs of shipbuilding enterprises. Furthermore, the classification and ranking of DRs provide insight guidance to enterprises on which DRs should be prioritized. Based on the study results, special attention should be paid to four regards of cooperation and information sharing among supply chain members, emergency mechanism construction, continuous supplier supervision and responsibility definition, and use of logistics outsourcing strategies while improving supply chain flexibility. In fact, the literature on supply chain flexibility evaluation believes that supplier collaboration flexibility, manufacturing flexibility and supplier flexibility related to procurement flexibility have an important impact on enterprise performance, which is also confirmed by the research conclusion of this paper. The reason may be that the downstream supply chain activities can only be implemented if the upstream material supply plan is guaranteed to be met.

\section{Conclusions}

In the shipbuilding industry environment, ensuring that ships are delivered on time has always been the focus of research. The procurement, transportation, and storage of a large number of materials involved in the ship construction process makes the supply network increasingly complex, which puts forward high requirements on resource integration capabilities, project management, and information management capabilities of shipbuilding enterprises. In order to overcome uncertainties in the supply environment to a certain extent, this paper employs a hybrid fuzzy DEMATEL-QFD method to construct a supply chain of shipbuilding materials with flexible characteristics, which provides decision-makers with a lot of knowledge on flexible strategies and helps managers to handle fluctuating supply chain environment effectively. 
First, this paper sets up comprehensive CRs for shipbuilding enterprises and constructs systematic flexibility enabling index from aspects of organizational flexibility, supply flexibility, logistics flexibility and quality flexibility based on the method of literature analysis and practical investigation. Additionally, the results reveal domestic procurement, collaboration among supply chain members, long-term strategic partnership with Suppliers, changeover among various suppliers regarding price, production and quality and strategic logistics outsourcing strategies show outstanding performance in dealing with uncertainty, which indicates that managers should pay special attention to material procurement strategy, supplier management, supply chain integration and logistics outsourcing. Second, the introduction of the fuzzy DEMATEL method takes into account the ambiguity of evaluation results and the asymmetry of influence relationship between factors, which is conducive to more accurately determine DRS of the target demand in the supply chain. In addition, this hybrid method can also be regarded as a flexible tool that organically combines the multi-dimensional flexible strategies of the supply chain with the actual demand index and is capable of quantitatively describing the relationship between the two. The effectiveness of this method is proved by practical research as it takes into account different requirements of ship enterprises in terms of material quality, arrival and schedule change. Actually, such a demand-oriented method will provide better guidance for decision-making. Third, the method can well cope with the complicated relationship among indicators and is easy to be applied in practice. From the perspective of shipbuilding enterprises, it can utilize the fuzzy DEMATEL-QFD method to convert its own demand into actual design requirements of the supply chain, so as to identify the best strategy for satisfying its interests. The proposed approach also provides an advantage that CRs and DRs can be modified for specific situations. In this regard, the application of this method to different fields of supply chain and comparative analysis of the corresponding research results will also reflect important significance.

In future research, different methods of achieving weights of CRs can be taken into account with the premise of the internal relationship between factors also considered. In addition, it is necessary to further explore specific practices of the important DRs identified, such as cooperation and information sharing of supply chain members, continuous supervision of suppliers, logistics outsourcing and construction of emergency mechanisms, etc.

Author Contributions: Conceptualization, J.Z. and H.W.; methodology, J.Z.; data curation, J.Z., H.W. and J.X.; formal analysis, J.Z. and H.W.; investigation, J.X.; writing-original draft preparation, J.Z.; writing-review and editing, H.W.; supervision, H.W.; project administraton, J.X. All authors have read and agreed to the published version of the manuscript.

Funding: Grant Number MC-202009-Z03 for this study.

Institutional Review Board Statement: Not applicable.

Informed Consent Statement: Not applicable.

Acknowledgments: The authors would like to express their special appreciation to all participants joining this study. We also thank the editors and the anonymous reviewers for their constructive suggestions on improving the paper.

Conflicts of Interest: The authors declare no potential conflict of interest.

\section{References}

1. Cheng, Z. Study on Categories and Characteristics of Cooperation Risks of the Shipbuilding Supply Chain. J. Jiangsu Univ. Sci. Technol. 2006, 2, 31-35.

2. Mello, M.H.; Strandhagen, J.O. Supply chain management in the shipbuilding industry: Challenges and perspectives. Proc. Inst. Mech. Eng. Part M J. Eng. Marit. Environ. 2011, 225, 261-270. [CrossRef]

3. Yue, W.; Zhang, Q. Research on the Shipbuilding Supply Chain Risk Control. In Proceedings of the 2008 IEEE International Conference on Automation and Logistics, Qingdao, China, 1-3 September 2008; pp. 2205-2208.

4. Fan, D.; Hu, Y. Shapley-value analysis of profit allocation in the shipbuilding supply chain. Harbin Gongcheng Daxue Xuebao/J. Harbin Eng. Univ. 2014, 35, 649-653. 
5. Merschmann, U.; Thonemann, U.W. Supply chain flexibility, uncertainty and firm performance: An empirical analysis of German manufacturing firms. Int. J. Prod. Econ. 2011, 130, 43-53. [CrossRef]

6. Jayant, A.; Ghagra, H.S. Supply Chain Flexibility Configurations: Perspectives, Empirical Studies and Research Directions. Int. J. Supply Chain. Manag. 2013, 2, 21-29.

7. Manuj, I.; Mentzer, J.T. Global supply chain risk management strategies. Int. J. Phys. Distrib. Logist. Manag. 2008, 38, 192-223. [CrossRef]

8. Christopher, M.; Peck, H. Building the Resilient Supply Chain. Int. J. Logist. Manag. 2004, 15, 1-13. [CrossRef]

9. Schoenherr, T.; Tummala, V.; Harrison, T.P. Assessing supply chain risks with the analytic hierarchy process: Providing decision support for the offshoring decision by a US manufacturing company. J. Purch. Supply Manag. 2008, 14, 100-111. [CrossRef]

10. Rao, T.; Schoenherr, T. Assessing and managing risks using the Supply Chain Risk Management Process (SCRMP). Supply Chain Manag. 2011, 16, 474-483.

11. Ferreira, F.D.A.L. An Empirical Risk Analysis of the Brazilian Shipbuilding Industry. Ph.D. Thesis, Programa de Pós-Graduação em Engenharia de Produção of the Departamento de Engenharia Industrial, Pontifical Catholic University of Rio de Janeiro (PUC-RIO), Rio de Janeiro, Brazil, 2015.

12. Zhang, Q.; Yue, W. Research on the Shipbuilding Agile Supply Chain Management System. In Proceedings of the International Conference on Wireless Communications, Shanghai, China, 21-25 September 2007.

13. Dainty, A.R.; Millett, S.J.; Briscoe, G.H. New perspectives on construction supply chain integration. Supply Chain Manag. Int. J. 2001, 6, 163-173. [CrossRef]

14. Zhao, J.; Sun, Y.Q. The Analysis and Countermeasures for Supply Chain Risk of Shipbuilding Industry. Logist. Sci-Tech 2008, 9, 96-99.

15. Crispim, J.; Fernandes, J.; Rego, N. Customized risk assessment in military shipbuilding. Reliab. Eng. Syst. Saf. 2020, 197, 106809. [CrossRef]

16. Ferreira, F.D.A.L.; Scavarda, L.F.; Ceryno, P.S.; Leiras, A. Supply chain risk analysis: A shipbuilding industry case. Int. J. Logist. Res. Appl. 2018, 21, 542-556. [CrossRef]

17. Yi, C.Y.; Ngai, E.W.; Moon, K. Supply chain flexibility in an uncertain environment: Exploratory findings from five case studies. Supply Chain Manag. Int. J. 2011, 16, 271-283. [CrossRef]

18. Bauer, D.; Göbl, M. Flexibility measurement issues in supply chain management. J. Appl. Leadersh. Manag. 2017, 5, 1-14.

19. Das, S.K.; Abdel-Malek, L. Modeling the flexibility of order quantities and lead-times in supply chains. Int. J. Prod. Econ. 2003, 85, 171-181. [CrossRef]

20. Vickery, S.N.; Calantone, R.; Droge, C. Supply Chain Flexibility: An Empirical Study. J. Supply Chain Manag. 1999, 35, 16-24. [CrossRef]

21. Garavelli, A. Flexibility configurations for the supply chain management. Int. J. Prod. Econ. 2003, 85, 141-153. [CrossRef]

22. Kesen, S.E.; Kanchanapiboon, A.; Das, S.K. Evaluating supply chain flexibility with order quantity constraints and lost sales. Int. J. Prod. Econ. 2010, 126, 181-188. [CrossRef]

23. Seebacher, G.; Winkler, H. A capability approach to evaluate supply chain flexibility. Int. J. Prod. Econ. 2015, 167, 177-186. [CrossRef]

24. Martinez, S.A.; Perez, M.P. Supply chain flexibility and firm performance: A conceptual model and empirical study in the automotive industry. Int. J. Oper. Prod. Manag. 2005, 25, 681-700. [CrossRef]

25. Lummus, R.; Rhonda, D.; Leslie, K. Supply Chain Flexibility: Building a New Model. Glob. J. Flex. Syst. Manag. 2003, 4, 1-13.

26. Gong, Z. An economic evaluation model of supply chain flexibility. Eur. J. Oper. Res. 2008, 184, 745-758. [CrossRef]

27. Duclos, L.K.; Vokurka, R.J.; Lummus, R.R. A conceptual model of supply chain flexibility. Ind. Manag. Data Syst. 2003, 103, 446-456. [CrossRef]

28. Yu, K. The effects of objective and perceived environmental uncertainty on supply chain flexibility. In Proceedings of the International Conference on Service Systems \& Service Management, Hong Kong, China, 3-5 July 2013.

29. Manders, J.H.; Caniëls, M.C.; Ghijsen, P.W.T. Exploring supply chain flexibility in a FMCG food supply chain. J. Purch. Supply Manag. 2016, 22, 181-195. [CrossRef]

30. Sreedevi, R.; Saranga, H. Uncertainty and supply chain risk: The moderating role of supply chain flexibility in risk mitigation. Int. J. Prod. Econ. 2017, 193, 332-342. [CrossRef]

31. Delic, M.; Eyers, D.R. The effect of additive manufacturing adoption on supply chain flexibility and performance: An empirical analysis from the automotive industry. Int. J. Prod. Econ. 2020, 228, 107689. [CrossRef]

32. Han, J.H.; Wang, Y.; Naim, M. Reconceptualization of information technology flexibility for supply chain management: An empirical study. Int. J. Prod. Econ. 2017, 187, 196-215. [CrossRef]

33. Shibin, K.T.; Gunasekaran, A.; Papadopoulos, T.; Dubey, R.; Singh, M.; Wamba, S.F. Enablers and Barriers of Flexible Green Supply Chain Management: A Total Interpretive Structural Modeling Approach. Glob. J. Flex. Syst. Manag. 2016, 17, 171-188. [CrossRef]

34. Fayezi, S.; Zutshi, A.; O'Loughlin, A. Developing an analytical framework to assess the uncertainty and flexibility mismatches across the supply chain. Bus. Process. Manag. J. 2014, 20, 362-391. [CrossRef]

35. Jain, V.; Wadhwa, S.; Deshmukh, S. Select supplier-related issues in modelling a dynamic supply chain: Potential, challenges and direction for future research. Int. J. Prod. Res. 2009, 47, 3013-3039. [CrossRef] 
36. Pujawan, I.N. Assessing supply chain flexibility: A conceptual framework and case study. Int. J. Integr. Supply Manag. 2004, 1, 79-97. [CrossRef]

37. Rajesh, R. Flexible business strategies to enhance resilience in manufacturing supply chains: An empirical study-ScienceDirect. J. Manuf. Syst. 2020, 60, 903-919.

38. Silbermayr, L.; Minner, S. A multiple sourcing inventory model under disruption risk. Int. J. Prod. Econ. 2014, 149, 37-46. [CrossRef]

39. Tachizawa, E.M.; Gimenez, C. Supply flexibility strategies in Spanish firms: Results from a survey. Int. J. Prod. Econ. 2010, 124, 214-224. [CrossRef]

40. Simatupang, T.; Wright, A.C.; Sridharan, R. The knowledge of coordination for supply chain integration. Bus. Process. Manag. J. 2002, 8, 289-308. [CrossRef]

41. Singh, R.; Kumar, P. Measuring the flexibility index for a supply chain using graph theory matrix approach. J. Glob. Oper. Strat. Sourc. 2019, 13, 56-69. [CrossRef]

42. Kanda, A.; Deshmukh, S.G. Supply chain coordination issues: An SAP-LAP framework. Asia Pac. J. Mark. Logist. 2007, 19, 240-264. [CrossRef]

43. Cachon, G.P.; Lariviere, M.A. Supply Chain Coordination with Revenue-Sharing Contracts: Strengths and Limitations. Manag. Sci. 2005, 51, 30-44. [CrossRef]

44. Kumar, P.; Shankar, R.; Yadav, S.S. Flexibility in global supply chain: Modeling the enablers. J. Model. Manag. 2008, 3, 277-297. [CrossRef]

45. Markus, F.; Frank, T.; Shaofeng, L. Digitization in maritime logistics-What is there and what is missing? Cogent Bus. Manag. 2017, 4, 1411066.

46. Yoo, S.H.; Kim, D.; Park, M.S. Pricing and return policy under various supply contracts in a closed-loop supply chain. Int. J. Prod. Res. 2014, 53, 106-126. [CrossRef]

47. Stratton, R.; Warburton, R. The Strategic Integration of Agile and Lean Supply. Int. J. Prod. Econ. 2003, 85, 183-198. [CrossRef]

48. Ramirez-Peña, M.; Sotano, A.J.S.; Pérez-Fernandez, V.; Abad, F.J.; Batista, M. Achieving a Sustainable Shipbuilding Supply Chain under I4.0 perspective. J. Clean. Prod. 2019, 244, 118789. [CrossRef]

49. Dikmen, I.; Birgonul, M.T.; Kiziltas, S. Strategic use of quality function deployment (QFD) in the construction industry. Build. Environ. 2005, 40, 245-255. [CrossRef]

50. Chan, L.-K.; Wu, M.-L. Quality function deployment: A literature review. Eur. J. Oper. Res. 2002, 143, 463-497. [CrossRef]

51. Sireli, Y.; Kauffmann, P.; Ozan, E. Integration of Kano' s Model Into QFD for Multiple Product Design. IEEE Trans. Eng. Manag. 2007, 54, 380-390. [CrossRef]

52. Park, S.; Lehto, X.; Lehto, M. Self-service technology kiosk design for restaurants: An QFD application. Int. J. Hosp. Manag. 2021, 92, 102757. [CrossRef]

53. Bottani, E.; Rizzi, A. Strategic management of logistics service: A fuzzy QFD approach. Int. J. Prod. Econ. 2006, 103, 585-599. [CrossRef]

54. Khalid, K.; Tarek, Z. An Integrated Assessment Approach to Prevent Risk of Sewer Exfiltration. Sustain. Cities Soc. 2018, 41, 576-586.

55. Wang, J.; Wu, H.; Chen, Y. Made in China 2025 and manufacturing strategy decisions with reverse QFD. Int. J. Prod. Econ. 2019, 224, 107539. [CrossRef]

56. Zarei, M.; Fakhrzad, M.; Paghaleh, M.J. Food supply chain leanness using a developed QFD model. J. Food Eng. 2011, 102, 25-33. [CrossRef]

57. Lam, J. Designing a sustainable maritime supply chain: A hybrid QFD-ANP approach. Transp. Res. Part E Logist. Transp. Rev. 2015, 78, 70-81. [CrossRef]

58. BuyukoZkan, G.; Berkol, Q. Designing a sustainable supply chain using an integrated analytic network process and goal programming approach in quality function deployment. Expert Syst. Appl. 2011, 38, 13731-13748.

59. Chowdhury, M.M.H.; Quaddus, M.A. A multiple objective optimization based QFD approach for efficient resilient strategies to mitigate supply chain vulnerabilities: The case of garment industry of Bangladesh. Omega 2015, 57, 5-21. [CrossRef]

60. He, L.; Wu, Z.; Xiang, W.; Goh, M.; Xu, Z.; Song, W.; Ming, X.; Wu, X. A novel Kano-QFD-DEMATEL approach to optimise the risk resilience solution for sustainable supply chain. Int. J. Prod. Res. 2020, 59, 1714-1735. [CrossRef]

61. Ramezankhani, M.; Torabi, S.A.; Vahidi, F. Supply chain performance measurement and evaluation: A mixed sustainability and resilience approach. Comput. Ind. Eng. 2018, 126, 531-548. [CrossRef]

62. Haiyun, C.; Zhixiong, H.; Yüksel, S.; Dinçer, H. Analysis of the innovation strategies for green supply chain management in the energy industry using the QFD-based hybrid interval valued intuitionistic fuzzy decision approach. Renew. Sustain. Energy Rev. 2021, 143, 110844. [CrossRef]

63. Prasad, K.D.; Subbaiah, K.V.; Rao, K.N. Supply chain design through QFD-based optimization. J. Manuf. Technol. Manag. 2014, 25, 712-733. [CrossRef]

64. Szymański, P. Risk management in construction projects. Procedia Eng. 2017, 208, 174-182. [CrossRef]

65. Sundara, M. Understanding Shipbuilding Supply Network. Asian J. Res. Bus. Econ. Manag. 2017, 7, 107-113. [CrossRef]

66. Gao, J.; Guo, F.; Ma, Z.; Huang, X. Multi-criteria decision-making framework for large-scale rooftop photovoltaic project site selection based on intuitionistic fuzzy sets. Appl. Soft Comput. 2021, 102, 107098. [CrossRef] 